\title{
Case of penetrating orbitocranial injury caused by wood
}

Erkan Mutlukan, Brian W Fleck, James F Cullen, Ian R Whittle

\begin{abstract}
A case of retained intraorbital and intracerebral wooden foreign body following an orbitocranial penetrating injury through the lower lid of an adult is described. Initial failure to recognise the true nature of the injury led to intracerebral abscess formation and monocular blindness. Diagnosis and management of such cases are discussed.
\end{abstract}

A fit 41-year-old male presented with a blunt injury to the right eye, and lacerations of the lower eyelid. He had fallen from a fence into some wooden foliage, but had not been concussed.

On examination the visual acuity was $20 / 30$ in the right eye and 20/20 in the left. Two splinters of wood were removed from small lacerations in the right lower eyelid. There was a slight ptosis. A $10 \mathrm{~mm}$ conjunctival laceration was present just inferior to the cornea. The sclera was intact. Abduction of the eye was normal, but all other ocular movements were limited. Corneal hypoaesthesia and a hyphaema were present, and the intraocular pressure was $50 \mathrm{mmHg}$. The pupil was oval, but reacted normally. The fundus was normal, as was the visual field to confrontation. The left eye was healthy. A skull $x$ ray did not show any abnormality.

The patient was admitted to an ophthalmology ward. The conjunctival and cutaneous lacerations were sutured, and oral acetazolamide was given to control the intraocular pressure.
Six hours later the patient became pyrexial, with a temperature of $39^{\circ} \mathrm{C}$, and his conscious level deteriorated to Glasgow Coma Scale 9. He was therefore transferred to the regional neurosurgery department.

An extradural haematoma was suspected, and a CT scan was performed. It showed right sided frontal lobe contusions with associated subarachnoid and intracerebral haemorrhage (Fig 1). Air was evident in the right orbit and adjacent to the intracerebral haematoma. A right frontal burr hole was made, which revealed contused cortex and subarachnoid haemorrhage. A subdural catheter was therefore inserted to monitor intracranial pressure. Microbiological examination of the catheter swab identified a Fusobacterium sp. and Leptotrichia buccalis.

The patient's pyrexia resolved with antibiotic treatment and his conscious level gradually improved to GCS 15 . However, he gradually developed a right proptosis, measuring $25 \mathrm{~mm}$ in the right eye (17 $\mathrm{mm}$ in the left) during the next five days. His visual acuity was reduced to hand movements, and a right afferent pupil defect developed. A repeat CT scan showed a mass situated superiorly and medially in the right orbit, thickening of the medial rectus muscle, and an orbital roof fracture (Figs 2, 3, 4). In addition a right frontal haematoma with surrounding oedema was present (Fig 5).

An emergency right frontal craniotomy, right optic canal decompression, and exploration of the right orbit were therefore performed through a superior orbitotomy. This revealed an abscess
Royal Infirmary of Edinburgh, Princess Alexandra Eye Pavilion E Mutlukan B W Fleck J F Cullen

Department of Clinical Neuro-Sciences, Western General Hospital, Edinburgh, Scotland I R Whittle

Correspondence to: DrE Mutlukan, Princess Alexandra Eye Pavilion, Edinburgh EH3 9HA. Accepted for publication 13 November 1990
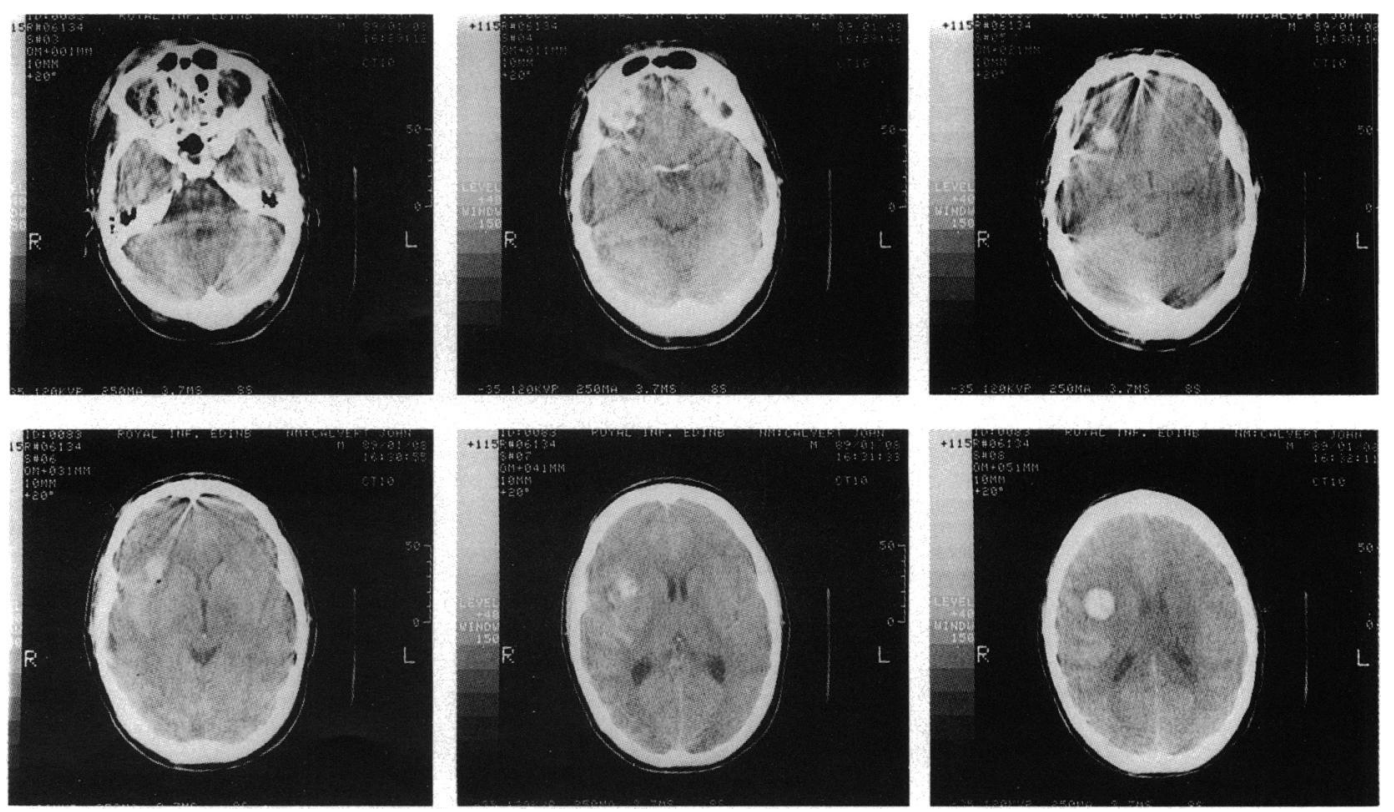

Figure 1 CT scan on the day of admission showed right frontal contusion with associated subarachnoid and intracerebral haemorrhage. Air was evident in the right orbit and intracranially. 

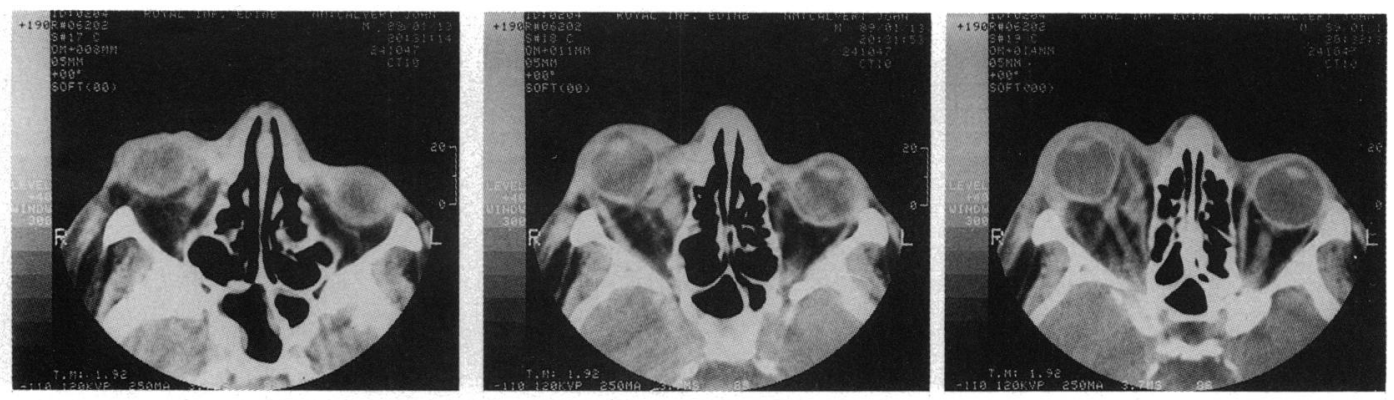

Figure 2, 3, 4 A repeat $C T$ scan on the fifth day after injury showed a right

intraorbital mass extending superiorly and medially in the right orbit, associated
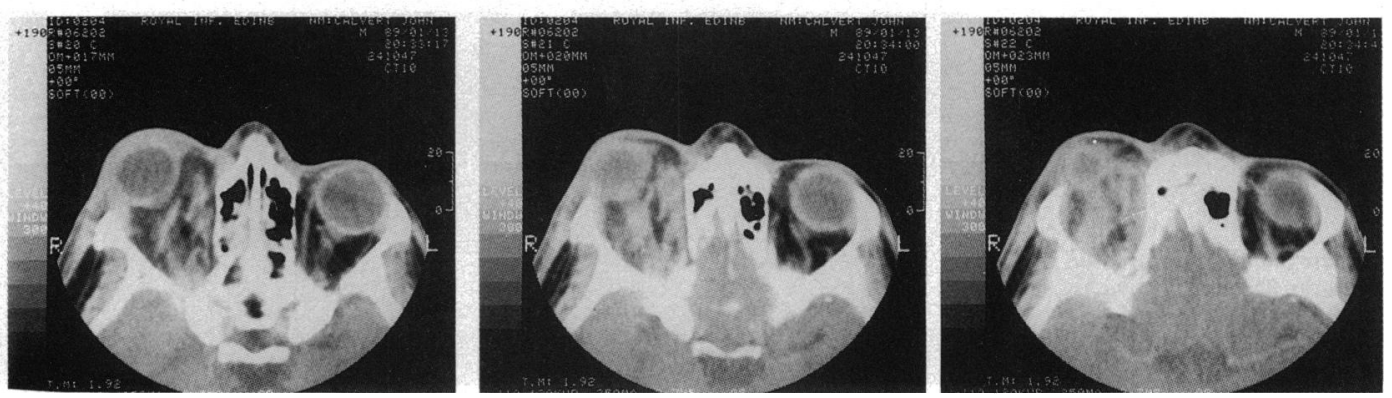

Figure 2

with thickening of the medial rectus muscle and an orbital roof fracture.

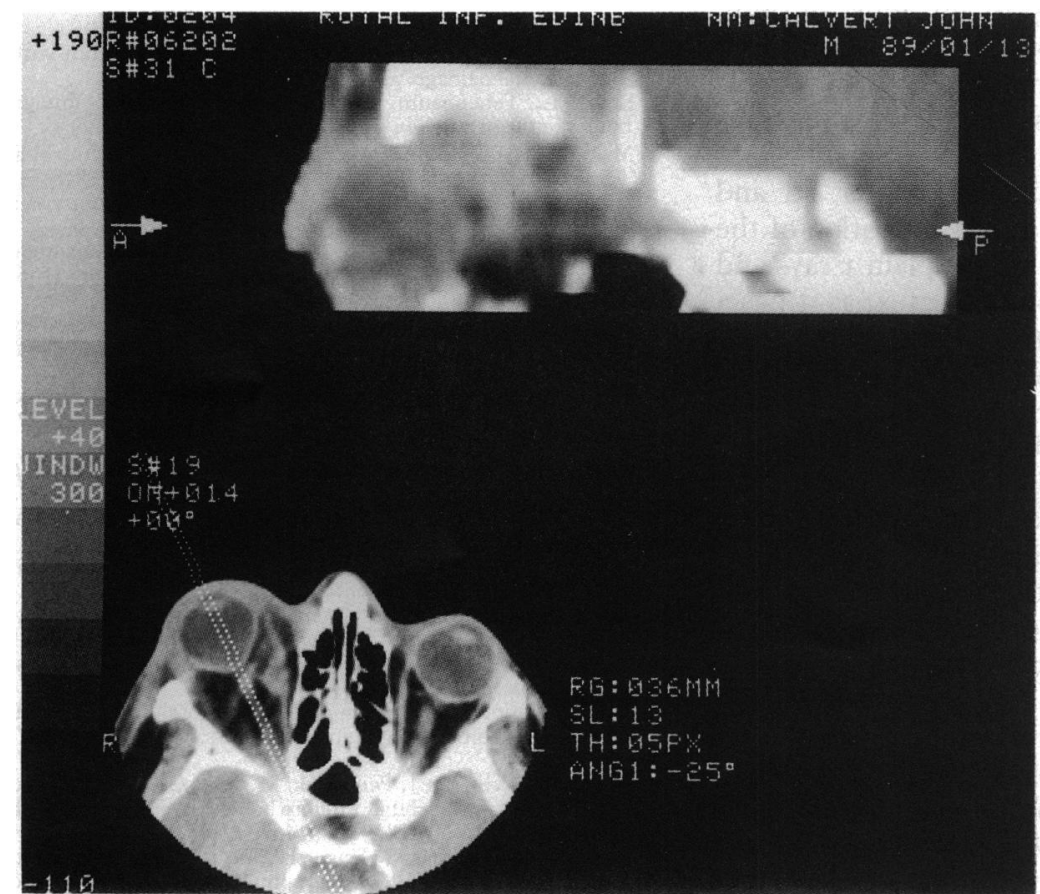

Figure 3 cavity which contained fragments of wood in the right frontal lobe. Multiple fragments of wood were also found in the posterior and inferomedial parts of the orbit. Pus from the brain abscess grew Bacteroides asaccharolyticus and small numbers of anaerobes.

Postoperatively the patient developed focal seizures, which responded to treatment with phenytoin. Further aspiration of the right frontal lobe abscess was performed with CT-imaged guided stereotaxy five weeks later. At the time of most recent follow-up the ptosis and exophthalmos had completely resolved, with full ocular movements, but the visual acuity in the right eye was no perception of light and optic atrophy had developed. There was no other neurological deficit.

\section{Discussion}

This case serves as a reminder that seemingly trivial injuries of the eyelids can be associated with severe lesions in the orbital region and shows the need to suspect intracranial penetration in orbital injuries. ${ }^{1-7}$

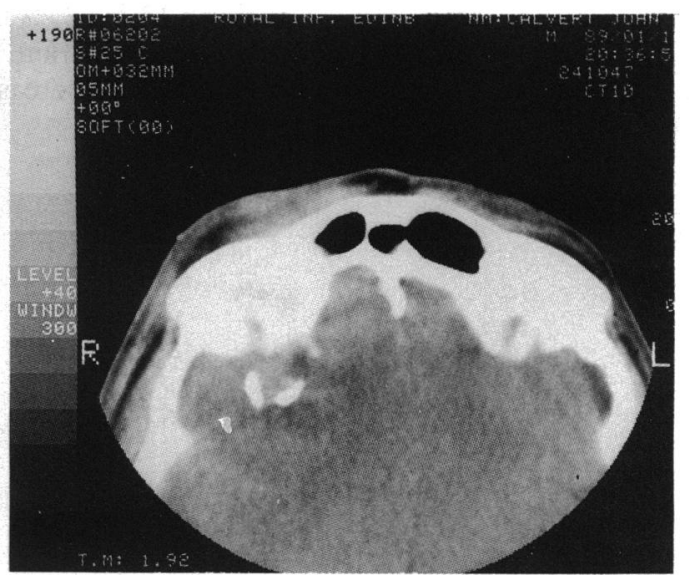


Figure 5 The right frontal intracerebral haematoma has prominent surrounding oedema five days after the injury.
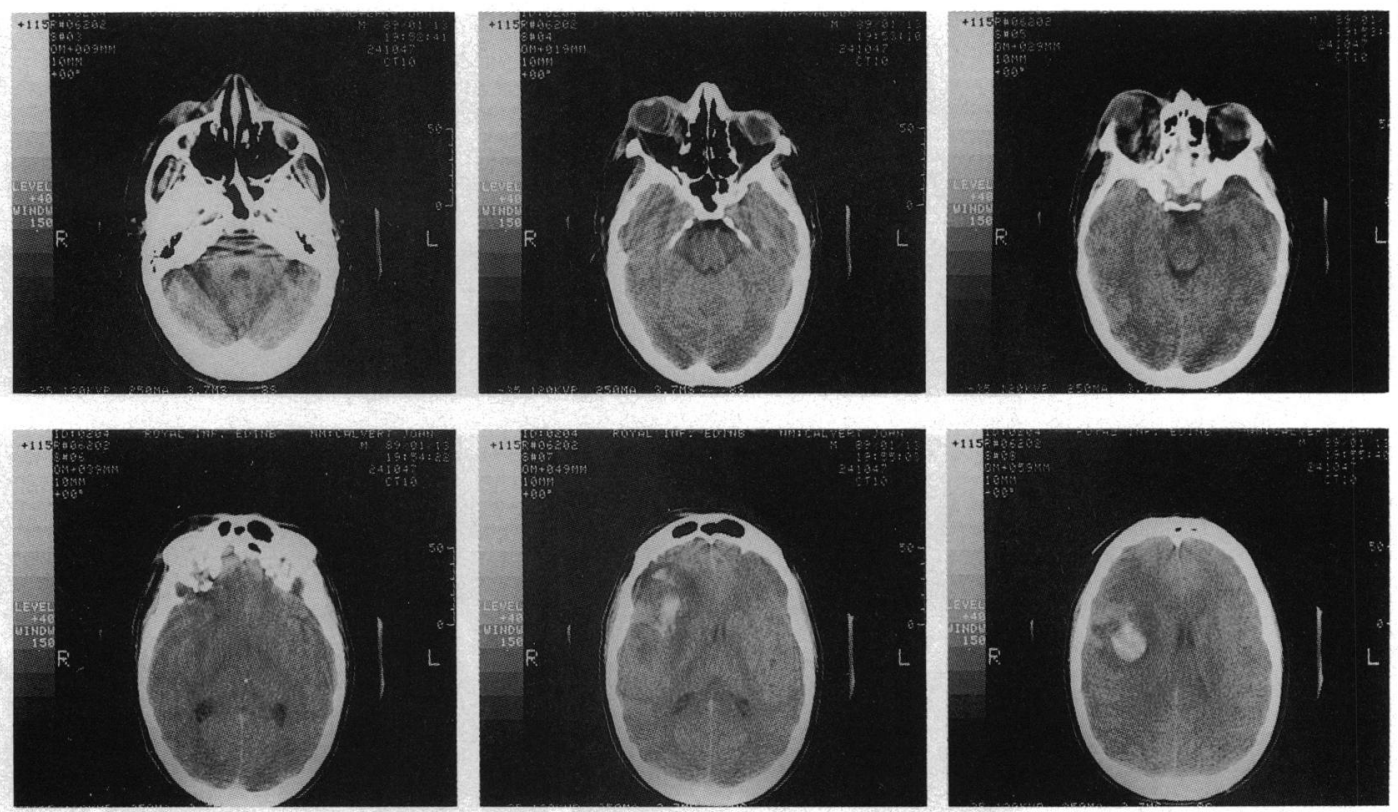

Transorbital intracranial penetration by a wooden foreign body is unusual. Previous cases with entry sites at the upper lid, inner or outer canthus, and without any ocular damage, as well as other types of orbitocranial injuries have been reported. ${ }^{16-12} \mathrm{We}$ are unaware of any previous report of wooden foreign body penetration into the cranial cavity through the lower lid and orbital roof in the absence of perforation of the globe. Wood is not detected on plain $x$ rays and very difficult to detect on CT scans, as it has a density very similar to that of intracranial and orbital soft tissue, especially after being present in an aqueous environment for $\mathbf{4 8}$ hours, when it has had time to absorb fluid. ${ }^{13-15}$ Ultrasound often does not detect orbital wood if it is dry and surrounded by air in the cavity. ${ }^{16}$ The value of magnetic resonance imaging in detecting intraorbital wood has recently been reported, and tion by a wooden foreign body and its retention are suspected. ${ }^{6}{ }^{17}$

All periorbital puncture wounds should alert the physician to the possibility of intracranial penetration. Intensive antibiotic therapy must be started immediately after all perforating orbital wounds by wooden objects even in the absence of any systemic and neurological signs, as the porous organic nature of the wood provides a dangerous natural reservoir for micro-organisms, causing a $12 \cdot 5-25 \%$ mortality rate secondary to intracranial infection. ${ }^{511} 18$ Antibiotics alone may not suffice, and there is a need for expeditious and MRI scanning has been advocated when penetra- thorough surgical exploration if retention of a wooden foreign body is suspected.

1 Gunkeltch AN. Apparently trivial wounds of the eyelids with intracranial damage. $\mathrm{BrMed} \mathcal{F} 1960$; ii: 842-4.

2 Broch L, Tenenbaum HL. Retention of wooden foreign bodies in the orbit. Can F Ophthalmol 1980; 15: 70-2.

3 Macrae JA. Diagnosis and management of a wooden orbital foreign body: case report. $\mathrm{Br} \mathcal{F}$ Ophthalmol 1979; 63: 848-51.

4 Horner FA, Berry RG, Frantz M. Broken pencil points as a cause of brain abcess. N Engl F Med 1964; 271 : 342-5.

5 Webster JE, Schneider RC, Lofstrom JE. Observations upon the management of orbitocranial wounds. $₹$ Neurosurg 1946; 3: 329-36.

6 Yamashita T, Kadota K, Asakura T, Ohba N. Penetrating orbitocranial injury: report of a case by a chopstick. Orbit 1988; 7: 59-64

7 Schneider RC, Henderson JW. Penetrating orbital wound with intracranial complications. Arch Ophthalmol 1952; 47 81-5.

8 Duffy GP, Bahandari YS. Intracranial complications following transorbital penetrating injuries. Brf Surg 1969; 56: 685-8.

Albert DM, Burns WM, Scheie HG. Severe orbitocrania foreign body injury. Am $\mathcal{F}$ Ophthalmol 1965; 60: 1109-11.

10 Bowen DI. Self inflicted orbitocranial injury with a ball point plastic pen. Br f Ophthalmol 1971; 55: 427-30.

11 Bard LA, Jarrett WH. Intracranial complications of penetrat-

12 Bursick DM, Selker RG. Intracranial pencil injuries. Surg Neurol 1981; 16: 427-31. 493-5

14 Myllyla V, Pyhtinen J, Pajvansalo M, et al. CT detection and location of intraorbital foreign bodies: experiments with wood and glass. ROFO 1987; 146: 639-43.

15 Kuhns LR, Borlaza GS, Seigel RS, et al. An in-vitro comparison of computed tomography, xero-radiography and radiography in the detection of soft-tissue foreign bodies. Radiology 1979; 132: 218-9.

16 McQuown DS. Ocular and orbital echography. Radiol Clin North Am 1975; 13: 523-41.

17 Green BF, Kraft SP, Carter KD, et al. Intraorbital wood detection by magnetic resonance imaging. Ophthalmology 1990; 97: 608-11.

18 Miller CF II, Brodkey JS, Colombi BJ. The danger of intracranial wood. Surg Neurol 1977; 7: 95-103. ing orbital injuries. Arch Ophthalmol 1964; 71: 332-43.

13 Tate E, Cupples H. Detection of orbital foreign bodies with computed tomography: current limits. $A \mathscr{F} R$ 1981; 137:

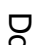

.

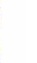

.

.

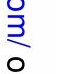

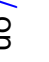
을.

,

రి

$$
\text { N }
$$
ర 